\title{
ENSINO (D)E HISTÓRIA INDÍGENA: UM LIVRO NECESSÁRIO
}

\author{
Maria Cristina Floriano Bigeli ${ }^{1}$
}

WITTMANN, Luisa Tombini (Org.). Ensino (d)e História Indígena. Belo Horizonte: Autêntica Editora, 2015.

Iniciar a introdução do livro Ensino (d)e História Indígena com a indagação "O que você sabe sobre os índios?", já nos põe em estado de reflexão antes mesmo de passarmos os olhos pelas primeiras frases contidas nessa seção. Afinal, o que a maioria de nós, professores ou não, porém, antes de tudo, brasileiros e brasileiras, sabe sobre os povos que outrora já habitavam essas terras? Além daqueles que possuem acesso a bibliografias especializadas, a população brasileira, majoritariamente, tem conhecimentos parcos e aquém do necessário. Para Wittmann, organizadora e autora de um dos capítulos do livro, a escassez de saberes a respeito dos povos indígenas brasileiros "[...] revela o desconhecimento de nossa sociedade sobre a própria história" (WITTMANN, 2015, p. 9). Contudo, há diversos motivos para tal insciência, sendo o principal deles a ausência ou a insuficiente abordagem de histórias e culturas indígenas em instituições educacionais.

Por décadas, os indígenas foram apartados da escrita da História do Brasil, portanto, pouco abordados nos currículos escolares. Quando apareciam nos livros e materiais didáticos, eram enfocados no passado, vistos como coadjuvantes e jamais como sujeitos históricos. Além disso, até meados de 1990, não havia menção aos indígenas em tempos anteriores à colonização espanhola e a portuguesa na América Latina na maioria dos livros didáticos brasileiros. Esses povos passavam a existir na História somente com a chegada dos estrangeiros e, consequentemente, a partir de seus olhares. No que se concerne à vinda dos povos indígenas ao continente americano, quase nenhuma informação era encontrada (GRUPIONI, 1996).

\footnotetext{
${ }^{1}$ Doutoranda UNESP - Assis. Professora UNESP - Marília.
} 
Dando mais um passo para trás, a exiguidade de estudos sobre indígenas na área de História pode estar relacionada ao imaginário construído com a chegada dos colonizadores, eternizado na famosa frase de Varnhagen, presente em História Geral do Brasil, livro de 1854: "de tais povos na infância não há história: há só etnografia" (VARNHAGEN, [1854] 1953, p. 31). Bittencourt (2013, p. 111-112) infere que, a partir dessa frase e dessa obra, "[...] poucos foram os historiadores que se ocuparam dos povos indígenas, assim como vários autores de livros didáticos se limitaram a reproduzir essa escassa produção sobre esses 'povos sem história', que tornaram-se, quase que exclusivamente, objeto de estudo de etnólogos". Corroborando, assim, com nosso atual desconhecimento acerca de histórias e culturas dos povos indígenas brasileiros.

Desde a metade final dos anos 1990, com a instituição dos Parâmetros Curriculares Nacionais (PCN), teve início uma reformulação do ensino brasileiro, bem como uma renovação nos ensinos fundamental e médio. A partir de então, passou-se a aceitar o termo "diversidade" como princípio norteador dos PCN para o ensino de História e, do mesmo modo, o termo "pluralidade" aparece em evidência. A temática indígena também é mencionada em diversos pontos, tanto nos PCN para as disciplinas de História e Geografia destinados aos primeiros ciclos do ensino fundamental (de $1^{a}$ a $4^{a}$ série, atualmente denominados de $1^{0}$ ao 50 ano), como nos PCN destinados à História dos anos finais do ensino fundamental ( $5^{\mathrm{a}}$ a $8^{\mathrm{a}}$ série, atuais $6^{\circ}$ ao $9^{\circ}$ ano).

A partir de tais parâmetros, diversos livros didáticos brasileiros incluíram conteúdos sobre indígenas em contextos anteriores à colonização europeia, passando a versar sobre o continente americano em temáticas relacionadas à Pré-história. Dessa forma, "a antiga tradição de começar nossa História com a chegada dos portugueses foi superada. Mantém-se, contudo, o predomínio da apresentação dos índios a partir do passado, mas isso se explica, em grande parte, por se tratar de livros de História" (FUNARI; PIÑóN, 2011, p. 100).

Anos após a publicação dos PCN, a lei 11.645/2008 torna obrigatório o estudo da história e cultura² ${ }^{2}$ ndígena nas escolas públicas e particulares. Assim, em colaboração com essa lei, o livro Ensino (d)e História Indígena tem o objetivo

\footnotetext{
2 Na lei é denominado "história" e "cultura" no singular. Nós optamos por sempre referenciar a "histórias" e "culturas" indígenas por partirmos da concepção de que os povos indígenas são diversos e plurais, sendo inadequado generalizar e considerar que todos os povos são iguais e possuem apenas uma história e uma cultura.
} 
de compartilhar e gerar conhecimentos a respeito da temática indígena, sendo uma obra destinada a professores e professoras da educação básica, principalmente para o ensino médio. Contudo, acreditamos que as diversas abordagens sobre povos indígenas, divididas em cinco capítulos, nos trás uma multiplicidade de informações sobre a pluralidade de histórias indígenas de nosso país e colaboram com aulas de todos os níveis escolares - inclusive com aulas universitárias.

$\mathrm{Na}$ introdução, Wittmann nos mostra o que está por vir a partir da discussão de uma nova área de estudos da temática: a Nova História Indígena. Essa área tem consolidado espaço nos estudos históricos por abordar ações e interpretações de sujeitos e povos indígenas diante de múltiplas realidades, além de buscar desconstruir afirmações até então bastante difundidas, tais como: "populações indígenas estão em vias de desaparecimento", "povos indígenas já fazem parte do passado", "extermínio indígena" ou mesmo visões "conservadoras", a saber, as que não consideram indígenas aqueles que deixaram de residir em suas terras e/ou comunidade de origem; aqueles que têm contato com objetos não indígenas que fazem parte da sociedade capitalista, como aparelhos eletrônicos (celulares, televisão, rádio, computador etc.), vestimentas (calça jeans, roupas íntimas, calçados, bonés etc.), automóveis, acesso a internet, entre outros. Ou seja, essas visões "conservadoras" não consideram indígenas aqueles que não mantiveram suas culturas estáticas (como se isso fosse possível!) e se apropriaram de objetos de outras culturas.

De fato, o livro cumpre o que propõe em seus cinco capítulos de autoria de pesquisadores e pesquisadoras com formação acadêmica em História. Nesses, as histórias e culturas indígenas são grafadas a partir de diversos olhares e abordam variadas regiões brasileiras, desconstruindo, de prontidão, as ideias de uma única história indígena ou de apenas uma cultura indígena. Além disso, percebe-se o cuidado com a diagramação da obra, pois os capítulos são constituídos de figuras coloridas e quadros informativos. Esses quadros são destacados do texto em caixas quadradas de cor púrpura e trazem informações, complementações e explicações essenciais para a compreensão dos assuntos abordados nos capítulos, ampliando, dessa forma, os conhecimentos dos leitores e tornando o assunto ainda mais dinâmico e compreensível. 
Vamos às análises desses trabalhos. Giovani José da Silva, autor do primeiro capítulo, intitulado "Ensino de História Indígena", após versar sobre as dificuldades em se reconhecer, no Brasil, a diversidade pluricultural e multiétnica, enfatiza a sua experiência em uma escola indígena localizada no Mato Grosso do Sul. Silva foi professor de ensino fundamental e médio da escola fixada na aldeia Bodoquena, dos indígenas Kadiwéu, na qual realizou uma experiência didático-pedagógica em História e a narra em seu capítulo. Entretanto, antes da experiência contada, o autor descreve suas dificuldades em se aprender o idioma falado pelos Kadiwéu - filiado à família Guaikuru - e também pela experiência que vivenciou ao acompanhar a instalação das escolas indígenas na região do Pantanal.

Com linguagem fácil para leigos, já que o livro não é destinado a acadêmicos e sim para docentes de escola básica, Silva explana algumas trocas de conhecimentos e experiências ocorridas durante sua permanência de sete anos nessa região do Mato Grosso do Sul. Ao final, assim como há nos capítulos seguintes, o autor propõe sugestões de atividades visando auxiliar os docentes na preparação das aulas escolares. Cada atividade possui um "texto de apoio para $o(a)$ professor(a)", que complementa o assunto abordado. Silva propõe atividades que vão além do assunto central de seu capítulo, ampliando a gama de possibilidades de se abordar História Indígena dentro da sala de aula. O autor sugere trabalhar, por meio de vídeo, a presença indígena na sociedade brasileira atual; refletir sobre as representações acerca dos indígenas presentes em canções; compreender os porquês das datas comemorativas, entre essas, o dia 19 de abril como "Dia do Índio"; realização de pesquisa a respeito da inserção da temática indígena nas aulas; e discussão de memórias construídas sobre a participação dos indígenas na Guerra do Paraguai. Enfim, há diversas propostas que os docentes podem se apropriar, se inspirar ou utilizar como norte para as aulas escolares.

Saindo do Centro-oeste e caminhando para região Norte do país, "Índios cristãos na Amazônia colonial", de autoria de Almir Diniz de Carvalho Júnior, aborda as relações ocorridas entre indígenas que habitavam a região amazônica e os europeus através das "missões católicas" - utilizadas como mais uma forma de colaborar com a conquista do território recém-"descoberto". Dentro dessas 
"missões" - núcleos de pequenos povoados instalados nas proximidades dos primeiros centros coloniais - havia uma maior concentração de indígenas do que de brancos (esses eram soldados, padres, missionários e alguns colonos), mas, obviamente, as impressões sobre tal período, registradas em documentos oficiais, vêm dos olhares dessas "minorias" brancas.

Deslocando o foco do olhar do europeu para o indígena, o autor do segundo capítulo descreve as relações e o dia a dia dentro desses lugares de "missões", como: as diversas funções cumpridas; os espaços de controle; a administração; as novas formas de conceber e administrar o tempo; o uso de panos de algodão para cobrir os corpos; a imposição de uma ética de trabalho que não condizia com os significados que os povos indígenas atribuíam a essas atividades laborais; as estratégias criadas para se livrarem dos serviços; ou seja, a imposição e a adaptação dos indígenas a essa lógica religiosa e cultural cristã. Portanto, os personagens, como diz o autor, obscurecidos na historiografia brasileira, são trazidos nesse capítulo para que compreendamos as transformações dos povos indígenas da região amazônica brasileira.

O terceiro capítulo, "Identidades indígenas no Nordeste", de Mariana Albuquerque Dantas, aborda as transformações nas identidades e culturas dos povos indígenas habitantes da localidade compreendida hoje como Nordeste, precisamente da região de Pernambuco, a partir da formação dos aldeamentos ocorrida no século XIX. Esse capítulo nos põe em estado de reflexão para entendermos as origens dos discursos que são disseminados, até a atualidade, a respeito da "pureza" dos indígenas. A autora também aborda o surgimento dos "caboclos" (remanescente de indígenas, na concepção daqueles que compreendem que a identidade é algo estático e imutável), as relações dos povos indígenas com o surgimento de aldeamentos, além do processo de extinção das aldeias articuladas pelos discursos acerca da mestiçagem.

Dantas constrói o texto de maneira didática, com figuras, mapas e documentos históricos, o que facilita tanto o processo de entendimento do professor como o do leitor que tenha interesse na temática. Além disso, a autora traz problematizações envolvendo os discursos dominantes das autoridades que ocupavam cargos administrativos e a falta de produções documentais a partir da fala dos indígenas, elucidando que, para se analisar fontes do século XIX a 
respeito da participação indígena na construção da História, é necessário que o leitor/pesquisador tenha um posicionamento crítico. Nas sugestões de atividades há a utilização de vídeos e da Literatura para se comparar imagens construídas acerca dos indígenas (como a imagem idealizada presente em "O Guarani", de José de Alencar, e a representação do povo mestiçado, considerado indolente e sem terra, contida no livro "O Caboclo", de Estêvão Pinto), além de textos de apoio para os docentes.

Luisa Tombini Wittmann, organizadora do livro, é a autora do quarto capítulo "Relações interétnicas ao Sul", que aborda histórias indígenas da região do Vale do Itajaí, localizado no estado de Santa Catarina. De escrita mais literária, o que possibilita uma leitura deveras agradável, a autora narra os "(des)encontros de dois mundos" - assim como a própria escreve - ocorridos entre o mundo dos indígenas Xokleng e o dos imigrantes europeus, majoritariamente alemães, que chegaram em Santa Catarina no século XIX. Além de informações sobre a criação de grupos denominados de "bugreiros", destinados à caça de indígenas, o que mais chama atenção, no capítulo, é a reconstrução das histórias de crianças indígenas retiradas de seus núcleos de nascimento para viverem nas cidades com outras famílias não indígenas com o intuito de serem "civilizadas". As histórias das irmãs Ana e Korikrã, duas indígenas Xokleng que foram retiradas do grupo para serem educadas com não indígenas (Ana recebeu o sobrenome alemão de Waldheim e foi viver junto às freiras no Colégio Sagrada Família e Korikrã foi adotada pela família Gensch) além de provocarem emoção no leitor, vêm a colaborar com a demonstração de como é incoerente ainda se dizer, no Brasil, que há "uma história indígena" (no singular), pois, as diversas etnias, os diversos povos, as diversas regiões brasileiras têm suas particularidades e suas diferentes histórias.

O último capítulo, escrito por Clovis Antonio Brighenti, "Movimento indígena no Brasil", aborda, além do assunto já explícito no título, os desafios para a consecução dos movimentos indígenas - como as demarcações de terras; a legislação indigenista no Brasil; a criação de órgãos como o Serviço de Proteção ao Índio (SPI) e a Fundação Nacional do Índio (FUNAI); as assembleias organizadas por Chefes Indígenas; as repressões e os apoios; e as diversidades dos movimentos indígenas devido às variedades de povos indígenas no Brasil. 
Um dos pontos importantes do texto é a desmistificação, já no início, da ideia do "bom selvagem", imbuída pelo pensamento europeu da época dos descobrimentos intramarinos (século XVI), demonstrando que os movimentos de resistências indígenas têm início no mesmo século, logo após a chegada dos portugueses.

O livro ainda possui, como anexo, uma série de "Materiais comentados sobre a temática indígena", no qual a organizadora visa auxiliar professores e estudantes para as reflexões acerca dos indígenas no ambiente escolar. Os materiais são divididos em: sites, músicas, mapas e filmes - com links daqueles que estão disponíveis para o domínio público em sites de internet.

Como já assinalado no início desta resenha, além de cumprir o objetivo de compartilhar e gerar conhecimentos sobre a temática indígena, o livro vai mais à frente. Colabora com a desconstrução de clichês como "o bom selvagem", mostrando as resistências e organizações indígenas surgidas a partir das próprias populações originárias; também favorece a desedificação de ideias que generalizam os povos indígenas, como se fossem todos iguais, evidenciando as diversas histórias e culturas presentes em várias regiões brasileiras; e põe em cheque a velha máxima de que esses povos estão desaparecendo, trazendo a tona reflexões acerca das identidades indígenas e das elaborações das mesmas.

A partir dos olhares de cinco pesquisadores, cada qual partindo da área de História, porém com diversas trajetórias acadêmicas e diferentes objetos de pesquisas, temos, neste livro, saberes que são essenciais para colaborar com a desconstrução de estereotipias sobre os indígenas e demonstrar algumas das produções da área de pesquisa intitulada Nova História Indígena. Compreendemos que, de tais povos, não há "história" no singular. Mas, há "histórias" no plural, há singularidades, há transformações, há lutas, há protagonismos, há presenças, há memórias, há sujeitos, há participantes da construção da História do Brasil, da constituição do povo brasileiro e da composição das diversas culturas que fazem parte de nosso país. Portanto, Ensino (d)e História Indígena é um livro necessário para brasileiros e brasileiras, sejam professores ou não. 


\section{Referências}

BITTENCOURT, C. F. História das populações indígenas na escola: memórias e esquecimentos. In PEREIRA, A. A.; MONTEIRO, A. M. (Org.). Ensino de história e cultura afro-brasileiras e indígenas. Rio de Janeiro: Pallas, 2013.

BRASIL. Lei no 11.645. "Altera a Lei no 9.394, de 20 de dezembro de 1996, modificada pela Lei no 10.639, de 9 de janeiro de 2003, que estabelece as diretrizes e bases da educação nacional, para incluir no currículo oficial da rede de ensino a obrigatoriedade da temática 'História e Cultura Afro-Brasileira e Indígena'. Disponível em: http://www.planalto.gov.br/ccivil_03/_ato20072010/2008/lei/l11645.htm> Acesso em: 13 de abril de 2014

- Ministério da Educação e do Desporto. Secretaria da Educação Fundamental. Parâmetros Curriculares Nacionais: ensino fundamental. Brasília: MEC/SEF, 10 volumes, 1997.

FUNARI, P. P.; PIÑóN, Ana. A temática indígena na escola: subsídios para os professores. São Paulo: Contexto. 2011.

GRUPIONI, L. D. B. Imagens Contraditórias e Fragmentadas: sobre o lugar dos índios nos livros didáticos. Revista Brasileira de Estudos Pedagógicos. Brasília, v.77, n. 186, p. 409-437, maio/ago. 1996.

VARnhAgen, F. A. de. História Geral do Brasil. Tomo 1. 5 ed. São Paulo: Melhoramentos, 1953.

WITTMANN, L. T. (Org.). Ensino (d)e História Indígena. Belo Horizonte: Autêntica Editora, 2015.

Recebido em 30 de maio de 2016

Aprovado em 31 de julho de 2016 